\title{
An Atypical Presentation of Massive Pulmonary Embolism
}

\author{
Tavishala Amarasimha Reddy, Wasil Rasool Sheikh, Meghna Haldar, Ankur Verma, Sanjay Jaiswal \\ Department of Emergency Medicine, Max Super Speciality Hospital, I.P.Extension, New Delhi, India.
}

\section{Corresponding Author:}

Dr. Tavishala Amarasimha Reddy

Email: amarasimhareddy@gmail.com

This is an Open Access article distributed under the terms of the Creative Commons Attribution License (creativecommons.org/ licenses/by/3.0).

March 15, 2018

\begin{abstract}
Background: Pulmonary embolism (PE) is an obstructive disease of the pulmonary arterial system caused by the embolization of thrombus originating from the deep veins of the lower extremities. Almost $25 \%$ patients of PE present with sudden cardiac death and not all patients may have classical symptoms. Hyper-coagulable states have been reported to cause cerebrovascular and myocardial thrombosis but rarely PE. Case Report: We present a case of a 27 year old male who presented to the Emergency Department with complaints of low backache and giddiness. Patient was found to be tachycardic, tachypneic and in shock. Patient had a low probability of PE with a Well's score of 1.5 but was diagnosed as having massive bilateral acute pulmonary embolism with deep vein thrombosis secondary to protein C deficiency. Conclusions: It is imperative for emergency physicians to have a high index of suspicion in young patients presenting with atypical symptoms and low clinical probability for PE in order to thrombolyse the patient on time
\end{abstract}

Keywords: Adult, Pulmonary Embolism, Protein C Deficiency, Pulmonary Artery, Venous Thrombosis.

\section{Introduction}

Pulmonary embolism (PE) is an obstructive disease of the pulmonary arterial system caused by the embolization of thrombus originating from the deep veins of the lower extremities [1]. PE is the third leading cause of cardiovascular related deaths after coronary arterial diseases and stroke [2]. Its incidence rises in older age group [3]. The frequency of developing pulmonary embolism in young patients is low but once developed it has a high potential for mortality if not diagnosed and managed early. Hyper-coagulable states like protein $\mathrm{C}$ and anti-thrombin III deficiency have been reported to cause cerebrovascular thrombosis but rarely been reported to cause PE. It is often a dilemma for emergency physicians whether or not to pursue the diagnosis of PE in patients who present with atypical signs and symptoms of pulmonary embolism. Despite diagnostic advances, delay in diagnosing pulmonary embolism is common and represent an important clinical issue. We report a case of a young male who presented with atypical symptoms with no co-morbidities and was diagnosed with PE and treated for the same.

\section{Case Report}

A 27 years old male patient was brought to the Emergency Department (ED) with history of left low backache since 2 days. He also complained of giddiness followed by a fall on the presenting day. There was no history of fever, chest pain or shortness of breath. The patient did not have any significant past medical or surgical history. He was an occasional smoker and there were no significant family history.

On examination the patient was tachycardic, tachypneic and in shock with a heart rate of 140/ min, respiratory rate of $34 / \mathrm{min}$ and unrecordable initial blood pressure. Patient was normo-thermic and saturating at $80 \%$ on room air. On secondary 
survey patient was pale and there was a lacerated wound over left occipital region and bilateral rhonchi were present on chest auscultation with bilateral equal air entry. Rest of the examination was unremarkable. Patient was started on oxygen inhalation and intravenous fluids to which the patient responded well.

ECG was done which showed sinus tachycardia and a chest x-ray showed haziness in the left lung base. To rule out a cardiac cause 2D echocardiography was done which showed dilatation of the right atrium and right ventricle and trace tricuspid regurgitation with normal ejection fraction [Fig.1]. Patients Well's score was 1.5 which comes under low probability group but keeping in view his echocardiography findings, he was further evaluated for PE. He had a D-dimer of $>5000 \mathrm{ng} / \mathrm{mL}(0.0-750.0)$ and subsequently Computed Tomography pulmonary angiography

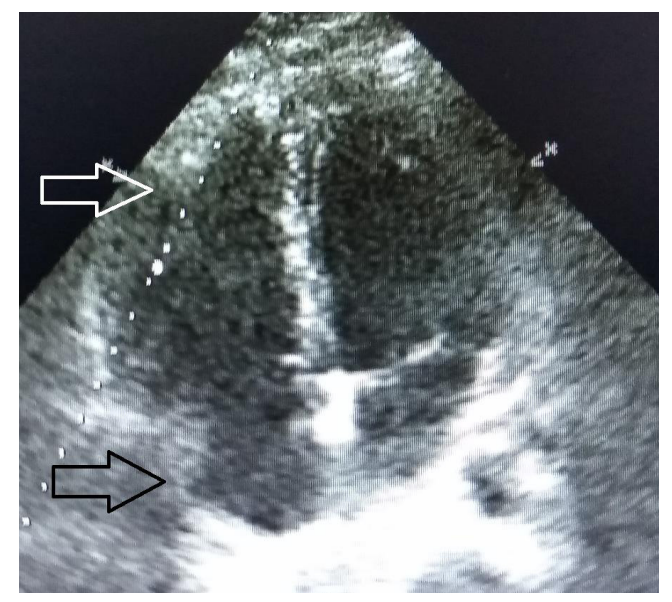

Fig.1: Echo showing $R A / R V$ dilatation.
(CT PA) was planned. The CTPA showed soft tissue density filling defect noted in the distal segment of the left main pulmonary artery extending upto the sub-segmental divisions of almost all lobes of left lung while on right side there was mild eccentric filling defect in the right middle lobar division not extending upto the sub-segmental level [Fig.2-5]. The patient was diagnosed with bilateral acute massive thromboembolism and was thrombolysed with tenecteplase. Doppler study of the lower limbs revealed a large echogenic thrombus in the right common femoral vein [Fig.6]. Patient was shifted to the Cardiac Care Unit for further management. Subsequent blood work revealed the patient to be deficient in protein $\mathrm{C}$ as 33\% (70-140) and antithrombin III as 35\% (83-128).

Patient was further managed conservatively with anti-coagulants and other supportive management. He responded well to given medical therapy and was discharged in a stable condition with the final diagnosis of massive acute bilateral pulmonary thrombo-embolism and deep vein thrombosis (DVT) secondary to protein C deficiency.

\section{Discussion}

The risk of blood clots is increased by cancer, prolonged bed rest, smoking, stroke, certain genetic conditions, estrogen-based medication, pregnancy, obesity, and after some types of surgery [4]. About $90 \%$ of emboli are from proximal leg DVTs or pelvic vein thromboses. Clinically apparent DVT is present in only $11 \%$ of confirmed cases of pulmonary embolism. The classic presentation
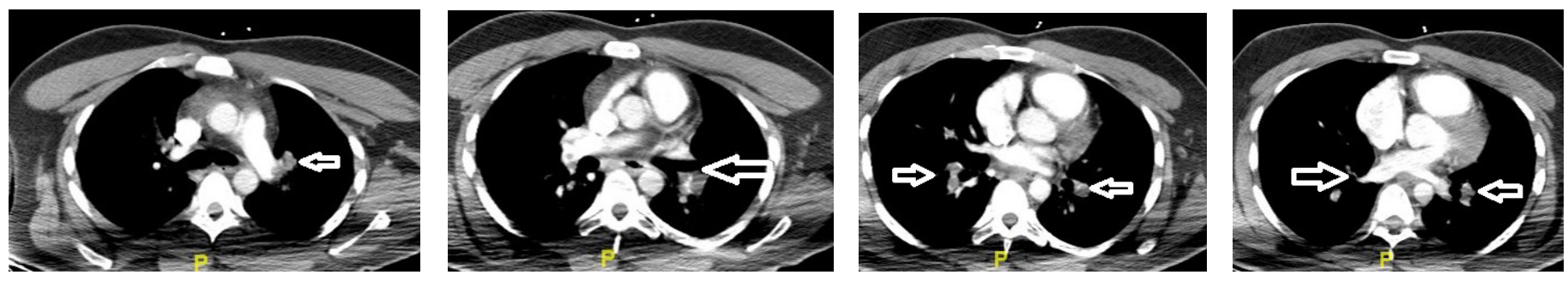

Fig.2-5: CTPA showing filling defect in the distal segment of the left main pulmonary artery extending up to the sub-segmental divisions of almost all lobes of left lung and mild eccentric filling defect in the right middle lobar division. 
of PE is the abrupt onset of chest pain, breathing difficulty and hypoxia but some patients may have no obvious symptoms at presentation. The diagnosis of pulmonary embolism should be suspected in patients with respiratory symptoms unexplained by an alternative diagnosis. Evidence-based literature supports the practice of determining the clinical pre-test probability of pulmonary embolism before proceeding with diagnostic testing [5]. The three validated systems include the Modified Wells Scoring System, the Revised Geneva Scoring System, and the Pulmonary Embolism Rule Out Criteria (PERC) [6-8]. Low probability PE can be ruled out with D-dimer testing [9]. CTPA is the gold standard for diagnosing pulmonary embolism [10].

A hyper-coagulation workup should be performed if no obvious cause for embolic disease is apparent and the patient does not have any risk factors for the same. Protein C is a $62-\mathrm{kD}$, vitamin $\mathrm{K}$-dependent glycoprotein synthesized in the liver. The activation of the protein into activated protein $\mathrm{C}$ (aPC) is catalyzed by thrombin when it is bound to the endothelial glycoprotein thrombomodulin $[11,12]$. The catalytic activity of aPC is greatly enhanced by the vitamin K-dependent cofactor protein S [13]. A deficiency of protein $\mathrm{C}$ disturbs the delicate balance between pro-coagulant and anti-coagulant proteins and engenders a prothrombotic state. Protein-C and anti-thrombin III deficiency leads to a three-fold to seven-fold increase in risk of thrombosis [14]. Protein C deficiency however leading to PE has rarely been reported. For almost one-quarter of PE patients, the initial clinical presentation is sudden death [15]. Early thrombolytic therapy has been shown to have beneficial outcomes in patients having massive PE.

\section{Conclusion}

In our case report, the patient had a Well's score of 1.5 and was found to have massive PE on CTPA along with DVT secondary to protein $\mathrm{C}$ deficiency. It is imperative for astute emergency physicians to

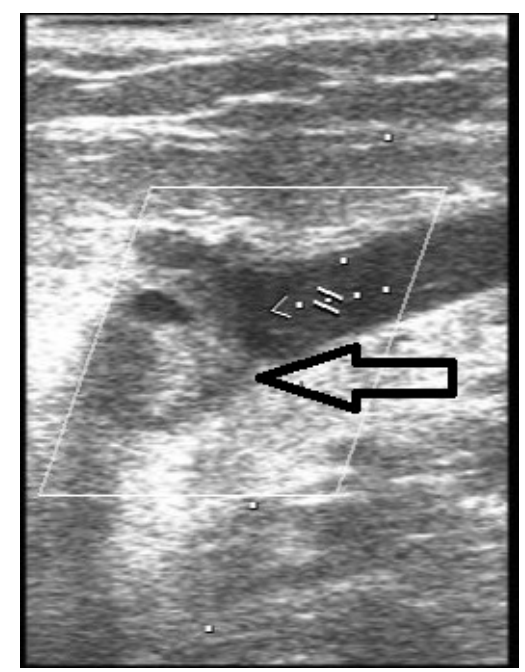

Fig.6: Doppler study showing large echogenic thrombus in the right common femoral vein.

have a high index of suspicion in young patients presenting with atypical symptoms and low clinical probability for PE in order to thrombolyse the patient on time.

Contributors: TAR: manuscript writing, patient management; WRS, MH: manuscript editing, patient management. AV, SJ: critical inputs into the manuscript. TAR will act as guarantor. All authors approved the final version of this manuscript.

Funding: None; Competing interests: None stated.

\section{References}

1. Dalen JE. Pulmonary embolism: what have we learned since Virchow? Natural history, pathophysiology, and diagnosis. Chest. 2002;122:1440-1456.

2. Konstantinides S. Acute pulmonary embolism. N Engl J Med. 2008;359:2804.

3. Anderson FA Jr, Wheeler HB, Goldberg RJ, Hosmer DW, Patwardhan NA, Jovanovic B, et al A populationbased perspective of the hospital incidence and case fatality rates of deep vein thrombosis and pulmonary embolism. The Worcester DVT Study. Arch Intern Med. 1991;151:933-938

4. Goldhaber SZ. Pulmonary thromboembolism. In: Kasper DL, Braunwald E, Fauci AS, et al. Harrison's Principles of Internal Medicine ( $16^{\text {th }}$ ed). New York, NY: McGrawHill. pp. 1561-1565.

5. Tapson VF. Acute pulmonary embolism. N Engl J Med. 2008;358:1037-1052.

6. Douma RA, Gibson NS, Gerdes VE, Büller HR, Wells PS, Perrier A, et al. Validity and clinical utility of the simplified Wells rule for assessing clinical probability 
for the exclusion of pulmonary embolism. Thromb Haemost. 2009;101:197-200.

7. Klok FA, Mos IC, Nijkeuter M, Righini M, Perrier A, Le Gal G, et al. Simplification of the revised Geneva score for assessing clinical probability of pulmonary embolism. Arch Intern Med. 2008;168:2131-2136.

8. Kline JA, Mitchell AM, Kabrhel C, Richman PB, Courtney DM. Clinical criteria to prevent unnecessary diagnostic testing in emergency department patients with suspected pulmonary embolism. J Thromb Haemost. 2004;2:1247-1255.

9. Moerloose P, Vanrusselt M, Reber G, Arnout J. Performaces of the HemosIL D-dimer HS assay for the exclusion of venous thromboembolism, J Thromb Haemost, 2005;3:2361-2363.

10. Kim KI, Muller NL, Mayo JR. Clinically suspected pulmonary embolism: utility of spiral CT. Radiology. 1999;210:693-697.
11. Dahlback B. Advances in understanding pathogenic mechanisms of thrombophilic disorders. Blood. 2008;112:19-27.

12. Clouse LH, Comp PC. The regulation of hemostasis: the protein C system. N Engl J Med. 1986;314:1298-1304.

13. Walker FJ. Regulation of activated protein $\mathrm{C}$ by a new protein. A possible function for bovine protein S. J Biol Chem. 1980;255:5521-5524.

14. Koster T, Rosendaal FR, Briet E, FJ van der Meer, Colly LP, Trienekens PH, et al. Protein C deficiency in a controlled series of unselected outpatients: an infrequent but clear risk factor for venous thrombosis (Leiden Thrombophilia Study). Blood. 1995;85:2756-2761.

15. Heit JA, Silverstein MD, Mohr DN, Petterson TM, O'Fallon WM, Melton LJ $3^{\text {rd }}$. Predictors of survival after deep vein thrombosis and pulmonary embolism: a population-based, cohort study. Arch Intern Med. 1999;159:445-453. 